\title{
MAMPUKAH INDONESIA BERSEPAKAT UNTUK MELAKUKAN PENINGKATAN SUMBERDAYA MANUSIA (SDM) YANG CERDAS DAN BERKUALITAS
}

\author{
Atmarita $^{1}$ \\ 'Direktorat Gizi Masyarakat, Depkes RI
}

\begin{abstract}
Malnutrition remains widespread and serious in Indonesia. It is almost halve of the Indonesian population suffer from several malnutrition forms and nearly $40 \%$ preschool children are stunted. Malnutrition influences a huge economic burden, investing in nutrition program is important for human development. However, Indonesia seems investing nutrition only as an intervention in health, agriculture, or social protection and not as an outcome measure of development. Nutrition is one of the most sensitive overall measures of poverty reduction, where this is defined as improving human development. This article analyzed secondary available data from National SocioEconomic Survey (SUSENAS) to present the evidence of missing opportunity in human development improvement program indicated by nutrition situation stays at the same figures even the prevalence of underweight tend to increased for the last 5 years. The assessment also showed that politically the government has committed to give more money to nutrition; however this commitment should be followed by bringing the involved stakeholders on nutrition to improve the quality of intervention in order to reach the targeted impact. It is recommended that Indonesia should start preparing complete information for reviewing strategy that will benefit to the community, provide policy analysis, as well as improving program management.
\end{abstract}

Keywords:

\section{PENDAHULUAN}

$\mathrm{M}$ asalah gizi di Indonesia masih sangat serius dan tersebar di seluruh wilayah

kabupaten/kota. Diperkirakan separuh dari penduduk Indonesia menderita berbagai bentuk masalah kurang gizi dan hampir $40 \%$ anak balita diklasifikasikan pendek. Pada tingkat keluarga, masalah kurang gizi ini akan sangat berpengaruh pada pengeluaran, terutama pada keluarga dengan anggota keluarga yang menderita masalah gizi dan sudah berinteraksi dengan infeksi.

Diketahui bahwa separuh dari kematian bayi dan balita disebabkan karena kurang gizi. Ironisnya bayi dan balita yang bertahan hidup, mereka tidak akan pernah menjadi manusia dewasa dengan potensi optimal untuk berpendidikan tinggi dan berproduktivitas. Indonesia dengan masalah gizi yang kronis akan selalu dihadapi dengan biaya kesehatan dan kesejahteraan yang tinggi, sementara upaya mengurangi kemiskinan akan selalu terhambat karena produktivitas sumberdaya manusia yang tidak bisa optimal.

Pada tataran global, seluruh negara, termasuk Indonesia sudah berjanji untuk mengatasi masalah gizi ini semenjak tahun 1974 pada "World Food Conference", kemudian tahun 1991 "World Summit for Children", resolusi tahun 1992 di "International Conference on Nutrition", selanjutnya tahun 2000 melalui "Millenium Declaration" untuk sepakat mencapai "Millenium Development Goals" yang 
diantaranya adalah menurunkan setengah dari masalah kurang gizi pada tahun 2015

Implementasi komitmen global untuk mengatasi masalah gizi di Indonesia nampaknya menghadapi berbagai kendala tercermin dari kualitas sumberdaya manusia yang lambat sekali peningkatannya. Hal ini sebenarnya dibuktikan juga dengan keadaan gizi penduduk yang cenderung memburuk, terutama sesudah tahun 2000. Kecenderungan meningkatnya masalah gizi ini juga diikuti dengan meningkatnya jumlah penduduk miskin.

Kesungguhan untuk melaksanakan komitmen global sebenarnya perlu diikuti dengan komitmen politik. Pada umumnya tercapainya komitmen politik dapat dinilai salah satunya dari alokasi yang cenderung meningkat untuk upaya perbaikan gizi. Indonesia, beberapa tahun terakhir berhasil membangun komitmen politik tersebut dimana alokasi program perbaikan gizi, khususnya di sektor kesehatan, meningkat cukup berarti.

Upaya berikutnya setelah komitmen politik terjadi, sebaiknya diikuti dengan strategi program perbaikan gizi yang berkualitas dan efektif. Yang terjadi di Indonesia, walaupun kebijakan dan strategi program cukup baik disusun, akan tetapi implementasi program seringkali kurang memperhatikan keberadaan petugas pelaksana yang umumnya tidak memadai. Dirasakan kemampuan manajemen program yang terbatas dari pimpinan wilayah dan jajarannya. Dengan demikian, membangun komit-men untuk peningkatan status gizi penduduk perlu dilakukan tidak saja untuk mempengaruhi politik, akan tetapi juga melibatkan proses yang diharapkan dapat juga mempengaruhi pemerintah, institusi pelaksana, dan masyarakat.

Kesempatan baik yang ditandai dengan terbentuknnya komitmen politik terkadang menjadi hilang jika program perbaikan gizi hanya memfokuskan pada pelaksanaan intervensi seperti apa adanya, tanpa memikirkan dampak yang akan dicapai dalam kurun waktu tertentu.

Berikut ini merupakan kajian sederhana untuk melihat apakah Indonesia mampu meningkatkan kualitas sumberdaya manusia dimasa yang akan datang berdasarkan kondisi yang sudah dicapai pada saat ini.

\section{BESARAN MASALAH SDM YANG DIHADAPI}

Berdasarkan urutan jumlah penduduk, Indonesia merupakan nega-ra besar keempat setelah Cina, India, dan Amerika Serikat. Pada tahun 2005, jumlah penduduk Indonesia mencapai 219,89 juta yang tersebar di 33 provinsi. Diperkirakan pada tahun 2025 penduduk Indonesia akan mencapai 273,22 juta. Tahun 2005, proporsi anak 0-4 tahun adalah 8,8\%, dan anak 5-14 tahun adalah $20,71 \%$. Mereka adalah calon SDM yang akan membangun Indonesia dan merubah kondisi SDM berikutnya pada kurun waktu setelah tahun 2025. Pada tahun 2025, diperkirakan proporsi kelompok usia muda akan menurun, dan penduduk akan mencapai umur yang lebih tua. Pada tahun 2025, diperkirakan proporsi anak 0-4 tahun menjadi 7,3\% dan anak usia 5-14 tahun 15\%. Sementara usia 65 tahun keatas akan menjadi 9,2\% tahun 2025 atau dua kali lipat dari posisi tahun 2005 yaitu $4,5 \%$.

Pertanyaan berikutnya, mampukan $20,7 \%$ anak ini membawa Indonesia ke situasi yang jauh lebih baik pada tahun 2025? Kebijakan dan strategi yang jelas memberikan dampak pada perbaikan kualitas SDM menjadi mutlak harus dilakukan. Dalam perjalanannya Indonesia dapat dikatakan sedikit berhasil merubah kualitas SDM melalui upaya perbaikan gizi. Secara nasional, program perbaikan gizi sudah berhasil menjangkau seluruh penduduk. Hal ini 
merupakan aset nasional yang seharusnya dipertahankan dan ditingkatkan.

Diketahui bersama bahwa tingginya masalah gizi pada penduduk, terutama dari kelompok umur di bawah lima tahun merupakan indikator sosial yang cukup jelas. Anak dengan kondisi gizi yang kurang baik kelak anak ini akan menjadi manusia dewasa dengan kualitas rendah. Walapun anak ini berasal dari keluarga yang mampu untuk mengikuti pendidikan sampai minimal usia 18 tahun, akan tetapi dengan kondisi gizi yang kurang baik, maka besar kemungkinan anak tersebut akan mengalami kesulitan. Dalam jumlah besar dampaknya adalah tingginya jumlah SDM yang kemungkinan tidak dapat menyelesaikan sekolah sampai jenjang SMA dan pada akhirnya adalah hilangnya kesempatan kerja yang baik. Pada anak perempuan, mereka akan menjadi ibu dan melahirkan kembali bayi dengan kualitas SDM rendah. Pada anak lakilaki, mereka akan masuk ke lingkup pekerja kasar dengan penghasilan rendah.

Seperti diuraikan sebelumnya anak 0-4 tahun pada tahun 2005 berjumlah $8,8 \%$ dari total penduduk 219,89 juta atau 19,35 juta. Berdasarkan Susenas tahun 2005, prevalensi gizi kurang (menurut berat badan dan umur) pada balita adalah $28,0 \%$ atau 5,42 juta balita. Secara keseluruhan bisa dilihat pada grafik berikut ini, yang menggambarkan rata-rata berat badan anak Indonesia pada tahun 2005 dan posisinya dibanding rujukan atau anak balita yang tumbuh normal.

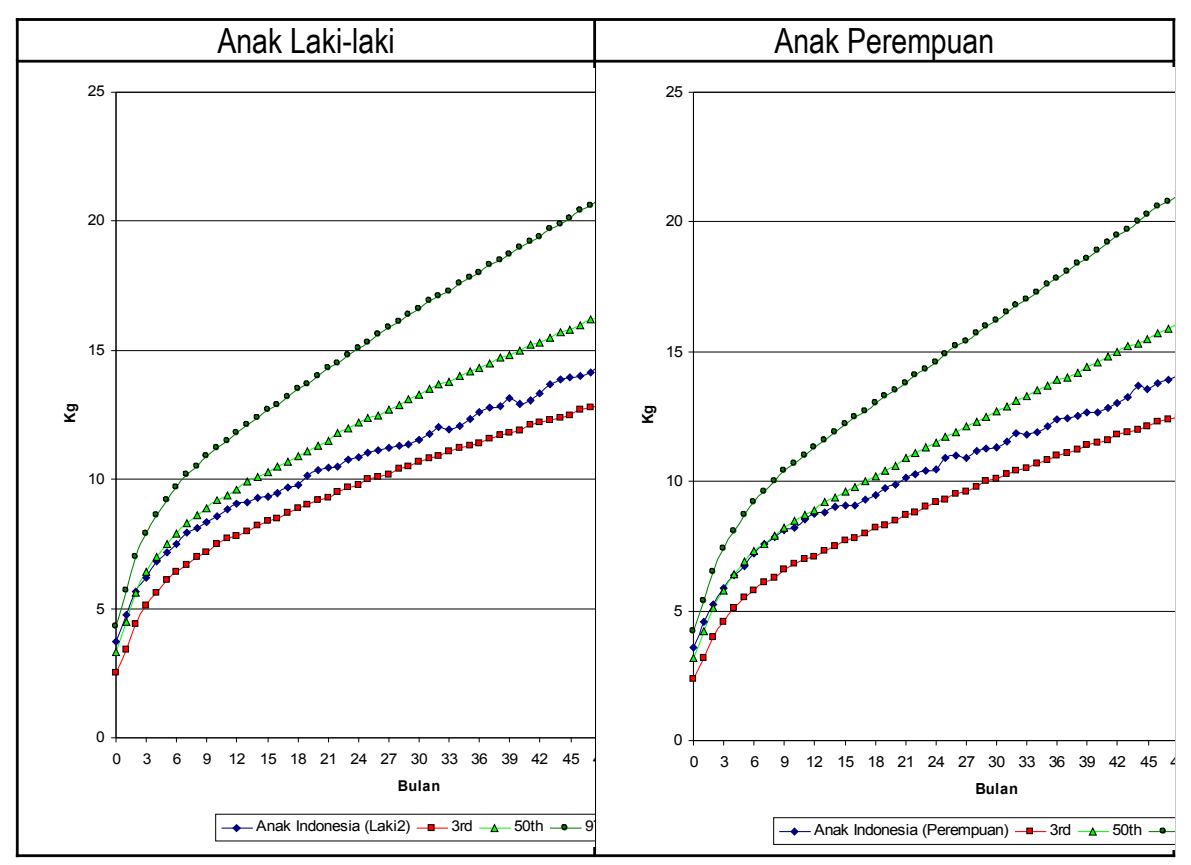

Gambar 1

Posisi anak balita Indonesia tahun 2005 dibanding rujukan

Dengan menggunakan rujukan yang dianjurkan $\mathrm{WHO}^{1}$, diharapkan anak mengikuti kurva normal pertumbuhan. Batas ambang terbawah adalah 3 percentile (3rd), rata-rata 50 percentile (50th)dan teratas 97 
percentile (97th). Dari gambar diatas bisa dilihat bahwa anak laki-laki mengikuti berat badan rata-rata hanya sampai usia 5 bulan dan seterusnya berkurang dan mendekati batas ambang terbawah. Pada anak perempuan, kondisi lebih baik dimana pertumbuhan mengikuti kurva normal sampai usia 11 bulan, akan tetapi pada akhirnya juga mendekati batas ambang terbawah. Hal ini terlihat dengan jelas pada grafik berikutnya (Gambar 2), bahwa anak Indonesia mengalami gagal tumbuh (growth faltering) setelah usia 5 bulan (anak laki-laki), dan 11 bulan (anak perempuan).

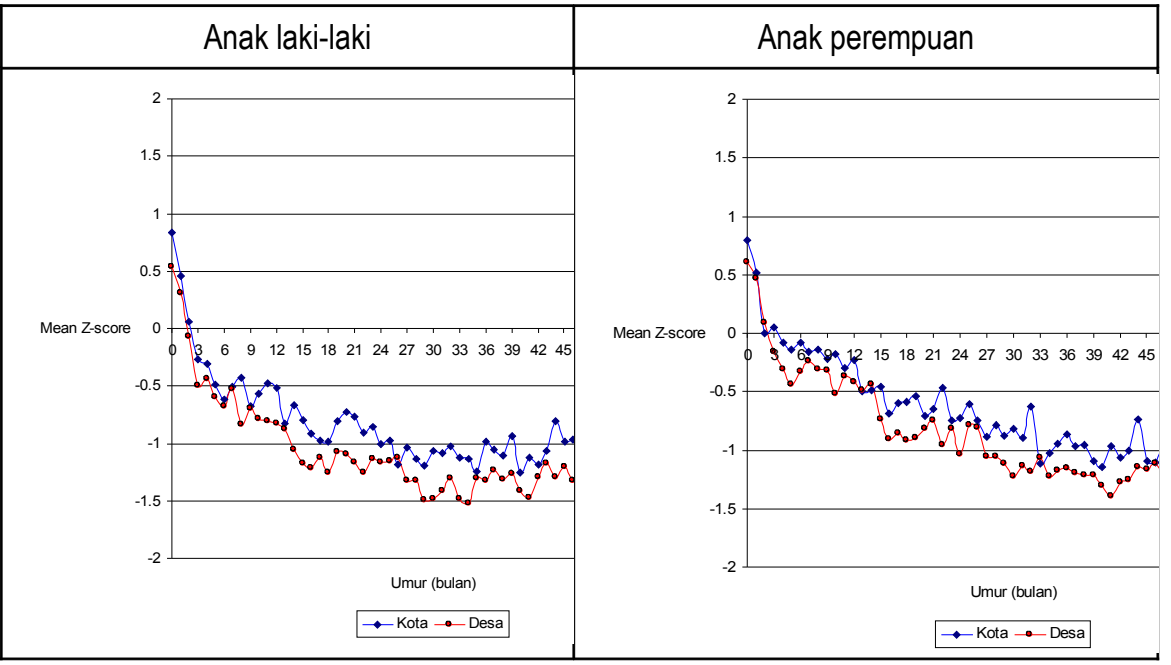

Gambar 2

Kejadian gagal tumbuh anak balita Indonesia tahun 2005 menurut Kota dan Desa

Kondisi berdasarkan tempat tinggal, terlihat anak di kota cenderung lebih baik dibanding anak di desa, walaupun kedua tempat memberikan gambaran yang sama dimana setelah usia 1 tahun kondisi anak Indonesia menjadi kurang menguntungkan. Keadaan gizi ini akan menjadi permanen dan berdampak pada SDM yang kurang berkualitas, cenderung tidak bisa mengikuti pendidikan sampai jenjang tertinggi. Seperti pada gambar 3 diperlihatkan kecenderungan anak perempuan 6-18 tahun yang tidak bersekolah lagi tahun antara tahun 1995 dan 2004. Pada akhirnya anak perempuan ini cenderung akan menikah, seperti yang diperlihatkan pada gambar 4, usia perkawinan pertama cenderung bergeser keusia yang lebih muda pada tahun 2004 dibanding tahun 1995.

Kondisi berdasarkan tempat tinggal, terlihat anak di kota cenderung lebih baik dibanding anak di desa, walaupun kedua tempat memberikan gambaran yang sama dimana setelah usia 1 tahun kondisi anak Indonesia menjadi kurang menguntungkan. Keadaan gizi ini akan menjadi permanen dan berdampak pada SDM yang kurang berkualitas, cenderung tidak bisa mengikuti pendidikan sampai jenjang tertinggi. Seperti pada gambar 3 diperlihatkan kecenderungan anak perempuan 6-18 tahun yang tidak bersekolah lagi tahun antara tahun 1995 dan 2004. Pada akhirnya anak perempuan ini cenderung akan menikah, seperti yang diperlihatkan 
pada gambar 4, usia perkawinan pertama cenderung bergeser keusia yang lebih muda pada tahun 2004 dibanding tahun 1995.

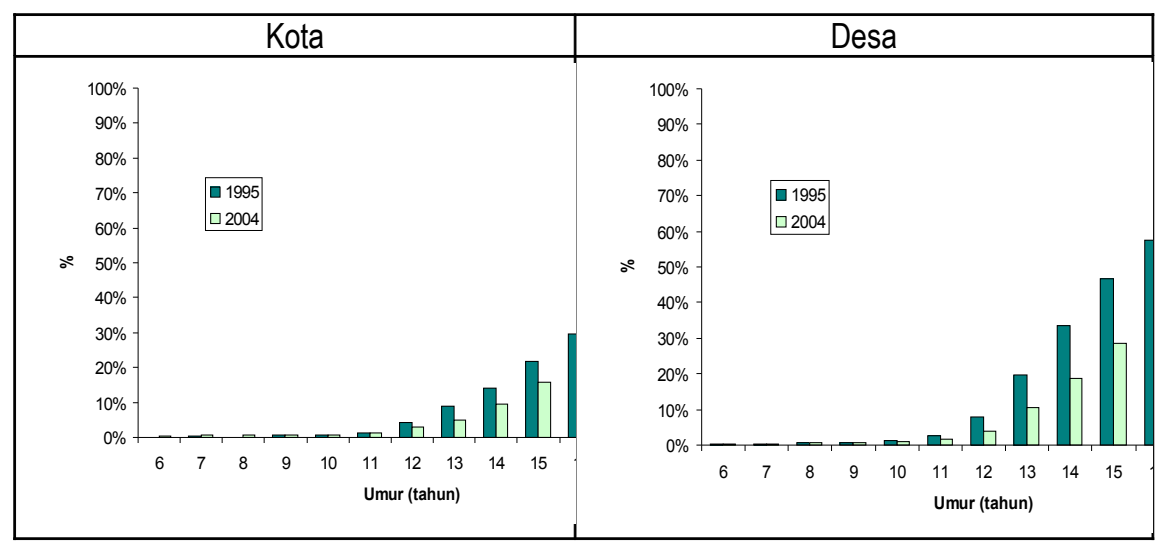

Gambar 3

Anak Perempuan 6-18 tahun tidak bersekolah lagi tahun 1995 dan 2004

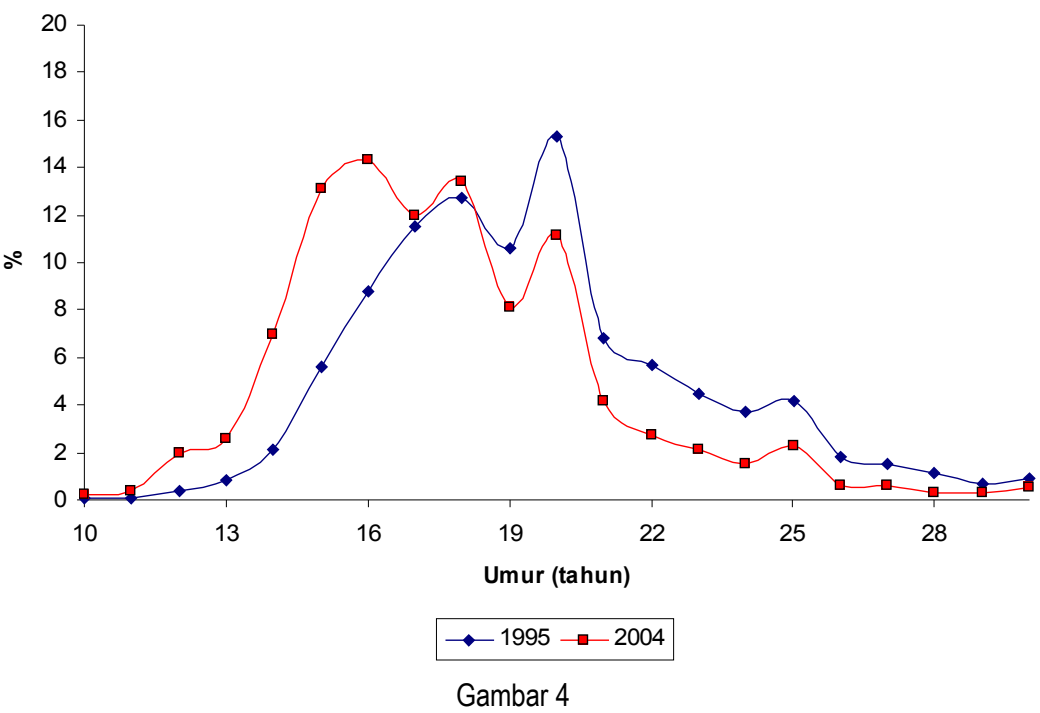

Umur Perkawinan Pertama Perempuan tahun 1995 dan 2004

Seperti yang telah diuraikan sebelumnya, terutama pada anak wanita, kejadian growth faltering yang terjadi pada bayi akan terus terakumulasi sampai usia berikutnya. Memasuki usia reproduktif 15 tahun, dapat dilihat pada grafik berikut (gambar 5) bahwa pada tahun 2005, dijumpai $32,5 \%$ wanita usia $15-19$ tahun mempunyai resiko kurang energi kronis $^{2}$. Mereka adalah calon ibu yang akan melahirkan bayi Indonesia berikutnya. Dan terlihat ada kecenderungan prevalensi risiko kurang energi kronis ini meningkat pada wanita usia

\footnotetext{
${ }^{2}$ Risiko Kurang Energi Kronis ditentukan berdasarkan Lingkar Lengan Atas/LILA $<23 \mathrm{~cm}$.
} 
20-24 tahun dan 25-29 tahun dari tahun 2003 ke tahun 2005.

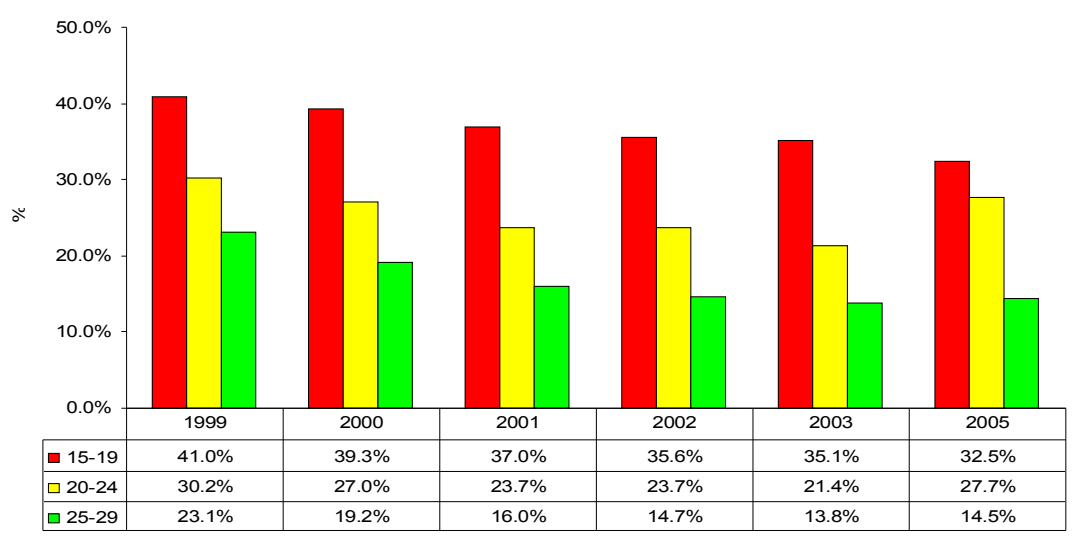

Gambar 5

Prevalensi Risiko Kurang Energi Kronis pada Perempuan usia 15-29 tahun, 1999-2005

Melihat kondisi SDM yang pada umumnya memburuk pada 5 - 10 tahun terakhir, sudah sepantasnya Indonesia melakukan penilaian terhadap program pembangunan yang telah dan sedang dilakukan sampai dengan saat ini. Cerminan memburuknya kondisi SDM ini juga diikuti dengan angka kemiskinan yang cenderung stabil semenjak tahun 2002 bahkan persentasi penduduk miskin tahun 2005 hampir sama dengan tahun 1987 (gambar6).

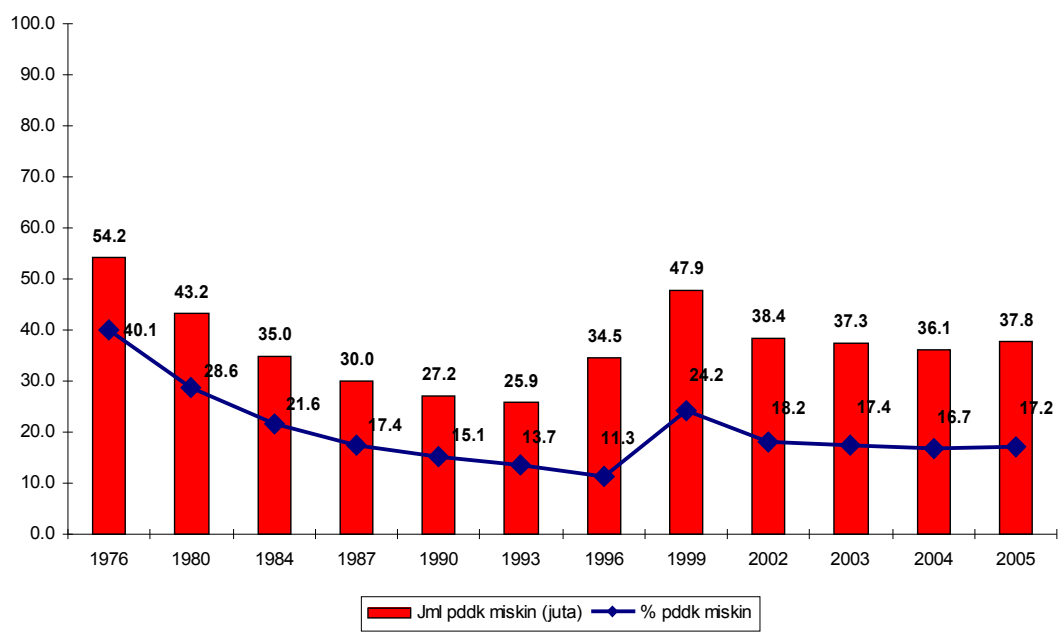

Sumber: BPS, 2006

Gambar 6

Penduduk Miskin Indonesia 1976-2005

Dari uraian di atas, terlihat dengan jelas bagaimana upaya peningkatan
SDM ini menjadi sangat penting. Jika tidak diantisipasi, Indonesia akan 
menjadi terpuruk yang ditandai dengan angka kemiskinan yang tidak berubah dan cenderung meningkat.

Pada sektor kesehatan, strategi yang ditetapkan tahun 2005 ini sangat komprehensif dengan visi dan misi yang sangat membumi yaitu "Masyarakat yang mandiri dan hidup sehat" (visi) dan "Membuat rakyat sehat" (misi). Visi dan misi ini didukung dengan 4 strategi besar:

1) Menggerakkan dan memberdayakan masyarakat untuk hidup sehat

2) Meningkatkan akses terhadap pelayanan kesehatan
3) Meningkatkan sistem surveilans, monitoring dan informasi kesehatan

4) Meningkatkan pembiayaan kesehatan

Bagaimana cara menterjemahkan strategi besar ini menjadi pokok kegiatan program yang membumi menjadi pertanyaan besar. Langkah baik yang sudah terlihat, misalnya saja dari program perbaikan gizi, paling tidak sudah terjadi komitmen politik, ditandai dengan meningkatnya alokasi yang diberikan seperti terlihat pada gambar 7.

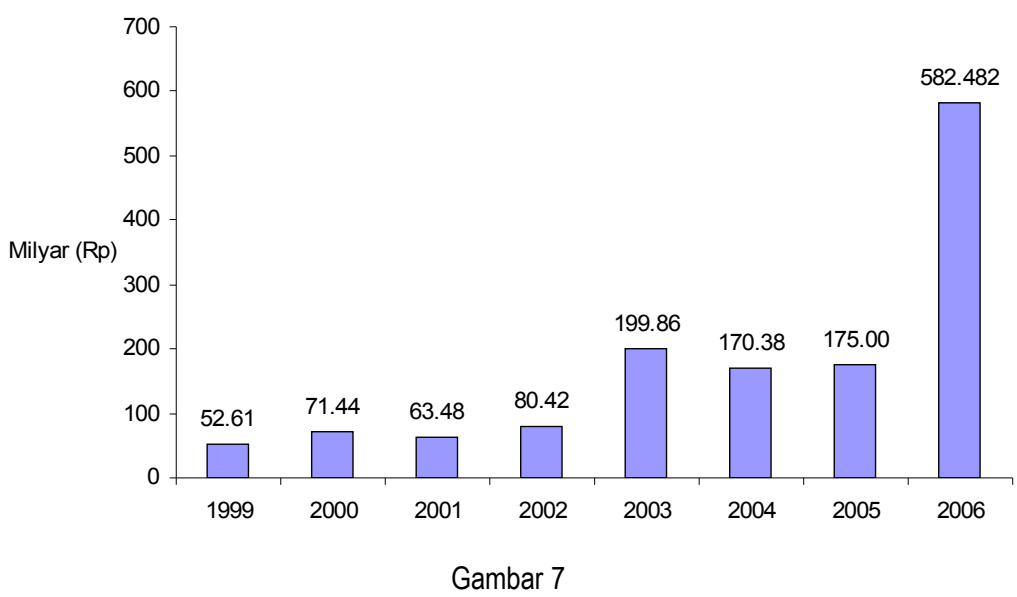

Alokasi Perbaikan gizi, sektor kesehatan 1999-2006

Persoalannya adalah alokasi ini tidak diterjemahkan menjadi kegiatan program strategis yang bisa berdampak pada peningkatan SDM. Bisa diamati seperti pada gambar 8 , bahwa proporsi terbesar (60\%) diberikan pada pemberian Makanan Pendamping Air Susu Ibu (MP-ASI) dan untuk lainnya
$(40 \%)$ dimanfaatkan untuk bermacammacam kegiatan yang terserak mulai dari surveilans, advokasi-sosialisasi, bimbingan tehnis, pertemuanpertemuan yang bertujuan untuk peningkatan kapasitas petugas, dan lain-lain. 


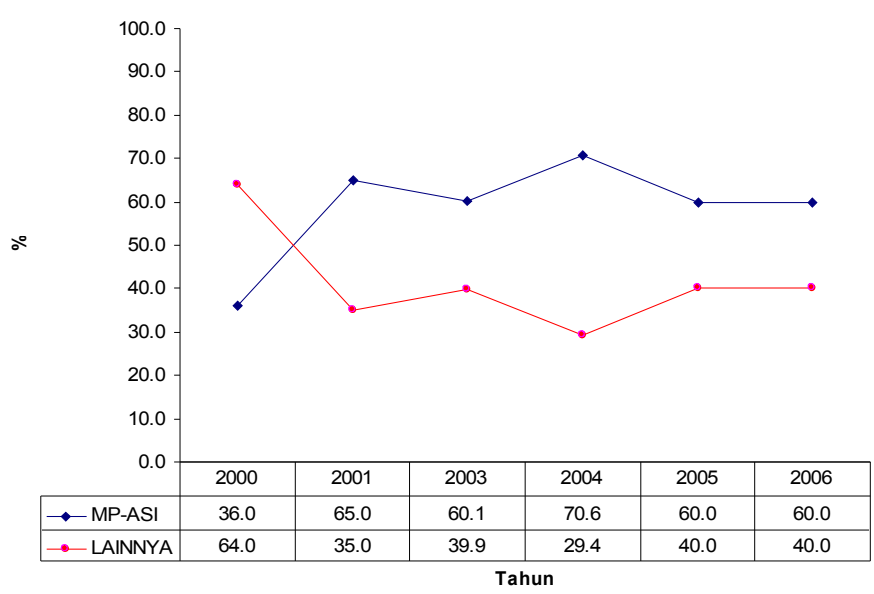

Gambar 8

Proporsi Alokasi Program Perbaikan Gizi 2000-2006

Implementasi dari strategi sektor kesehatan yang baru dicanangkan akhir tahun 2005 memang belum berdampak, terutama pada keadaan gizi penduduk Indonesia. Akan tetapi kedepan perlu dipikirkan hal ini, apalagi mengingat situasi Kabupaten/Kota di Indonesia yang sangat memprihatinkan seperti yang terlihat pada gambar 9 berikut ini.

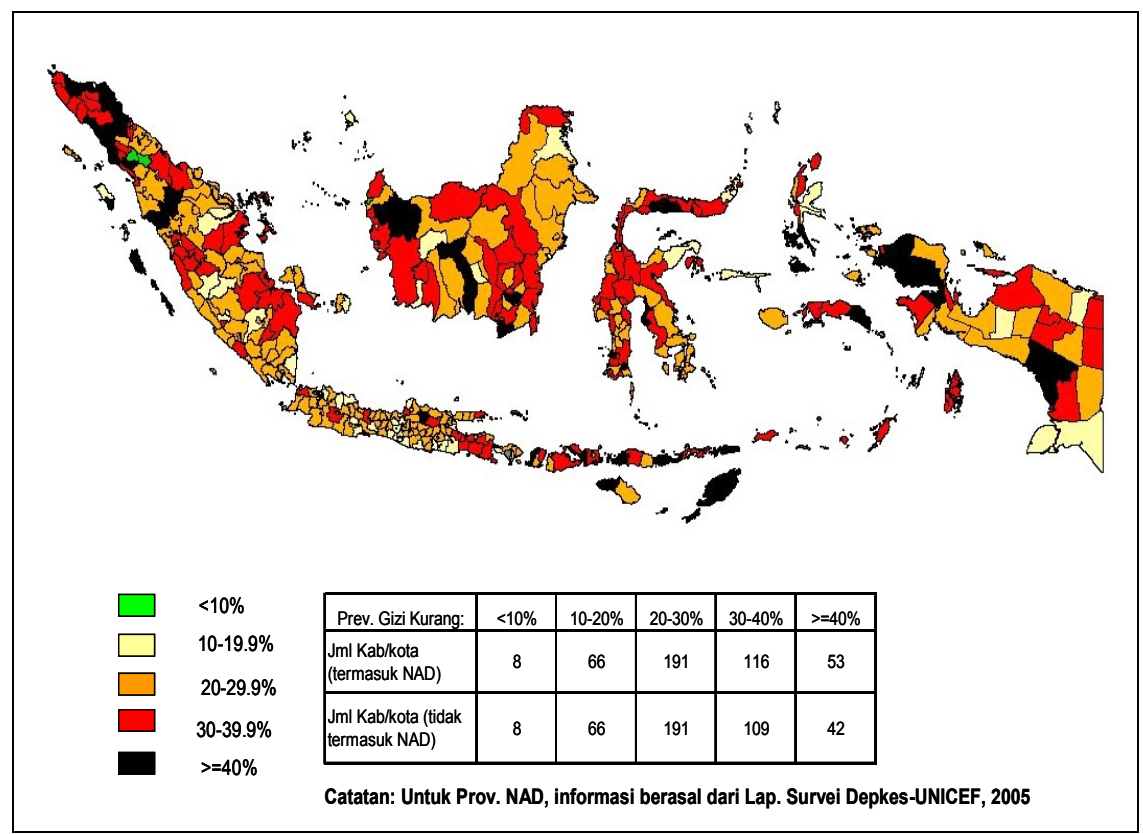

Gambar 9

Prevalensi Gizi Kurang (BB/U) anak balita menurut Kabupaten/Kota, 2005 
Upaya pemberdayaan masyarakat menjadi sangat penting. Selain untuk memperbaiki keadaan ekonomi, juga akan membawa masyarakat untuk aktif, minimal mau membawa anaknya ke Posyandu untuk memantau pertumbuhan agar dapat dilakukan intervensi segera jika terlihat gejala sangat dini dari gagal tumbuh. KADARZI (Keluarga Sadar Gizi) yang menjadi bagian untuk mencapai visi dan misi sektor kesehatan diharapkan dapat berhasil membawa seluruh anggota keluarga untuk mencapai gizi baik. Posyandu diharapkan menjadi unit terdepan untuk menggerakkan masyarakat mencapai tujuan tersebut. Pertanyaan selanjutnya bagaimana seluruh pimpinan wilayah dan jajarannya di Indonesia ini dapat berjalan bersama serta sepakat untuk melaksanakan dengan baik dan benar.

\section{KOMITMEN DAN PILIHAN STRATEGIS}

Besarnya masalah SDM yang telah diuraikan diatas menunjukkan rendahnya komitmen pemerintah berupaya untuk menurunkan masalah gizi. Ada beberapa kemugkinan mengapa hal ini bisa terjadi. Secara sederhana dapat diuraikan sebagai berikut:

1. Biasanya individu yang terkena masalah gizi terlihat "tidak sakit", walaupun sebenarnya individu ini "tidak sehat". Situasi seperti ini, mulai dari tingkat keluarga sampai kejenjang tertinggi pemerintahan mungkin tidak akan menyadari, sampai akhirnya dalam jumlah besar akan dirasakan misalnya tingkat pendidikan rendah, kemiskinan, dstnya.

2. Secara perlahan individuindividu yang kurang gizi akan memerlukan pengeluaran yang besar, karena pada akhirnya mereka akan sakit. Di tingkat keluarga ketika terjadi kematian anggota keluarga karena infeksi tertentu, diare, atau lainnya baru akan sadar bahwa penyebabnya antara lain karena kurang gizi.

3. Terkadang pemerintah hanya akan melakukan investasi yang dilakukan dengan cepat berkaitan dengan mengurangi kemiskinan atau meningkatkan pertumbuhan ekonomi tanpa berpikir bahwa kurang gizi sebenarnya yang menyebabkan kemiskinan atau pertumbuhan ekonomi negara menjadi terhambat. Sebenarnya ada investasi dalam bentuk upaya perbaikan gizi yang demikian murah seperti fortifikasi yang dikombinasikan dengan peningkatan pengetahuan atau pendidikan yang dapat mengurangi kemiskinan.

4. Dirasakan konsensus untuk mencegah masalah gizi bersama terkadang sulit tercapai. Insitusi yang pada umumnya sangat banyak terlibat untuk mengatasi masalah ini masing-masing akan melihat berdasarkan satu penyebab saja. Misalnya dari sektor kesehatan, mengatasi masalah gizi hanya berdasarkan penyakit, sehingga mengatasinya dilakukan dengan cara kuratif atau mengobati penyakit, bukan mencegah. Dari sektor pertanian melihatnya hanya dari sisi ketidaktahanan pangan, dan solusinya hanya meningkatkan produksi pangan.

5. Dukungan politik yang sangat sulit dicapai, hal ini biasanya karena kurangnya advokasi atau sosialisasi untuk kejelasan tentang masalah gizi dan solusinya dari pelaksana program.

6. Beberapa pimpinan wilayah mungkin mengatakan sudah melakukan upaya untuk peningkatan gizi masyarakat, yang sebenarnya belum dilakukan. 
Misalnya program yang dilakukan adalah subsidi harga pangan atau promosi produksi pangan dimana program ini dinyatakan telah membantu mengurangi masalah gizi, padahal yang sebenarnya target atau kelompok masyarakat yang beruntung bukanlah kelompok miskin.

Masih banyak alasan lain yang dapat menyebabkan komitmen peningkatan status gizi tidak tercapai yang pada dasarnya adalah karena rendahnya pengetahuan serta kesadaran para pelaku program.

Dari uraian di atas, sebenarnya strategi yang dilakukan Departemen Kesehatan pada akhir tahun 2005 untuk mencapai visi "Masyarakat yang mandiri dan hidup sehat" perlu didukung dengan kajian atau analisis agar dapat diperoleh program strategis yang mempunyai dampak pada SDM. Visi yang demikian membumi kemungkinan tidak akan tercapai jika reformasi kesehatan: i) tidak merencanakan program kegiatan yang tidak saling tumpang tindih, ii)mengalokasikan pembiayaan kesehatan hanya untuk pengobatan bukan pencegahan, iii) hanya melakukan distribusi pangan untuk perbaikan gizi, iv) tidak diciptakannya upaya yang bersifat proaktif untuk membangun demand masyarakat, dan lain-lain.

Untuk kedepan, jika SDM Indonesia akan dibangun, maka beberapa pendekatan perlu dipikirkan yaitu:

1. Advokasi dan komunikasi

Untuk mencapai komitmen maka informasi yang komprehensif tentang SDM dan permasalahannya serta solusi atau alternatif programnya perlu tersedia dan dipresentasikan atau disampaikan keseluruh individu, organisasi, insititusi yang terlibat. Alat yang berkaitan dengan Informasi, Edukasi, Komunikasi yang telah dirancang semenjak tahun 1970-an dan menjadi "social marketing" tahun 1980 , selanjutnya ditingkatkan lagi menjadi "Behavior Change Communication" tahun 1990-an perlu dijalankan atau diaplikasikan untuk membangun komitmen dalam upaya pengembangan progam yang bertujuan pada peningkatan SDM.

\section{Analisis kebijakan}

Berdasarkan informasi yang lengkap, analisis kebijakan untuk pengembangan program strategis mutlak dilakukan. Indonesia yang berpengalaman mengembangkan program perbaikan gizi sudah seharusnya dilakukan lagi dengan memperhatikan situasi wilayah dan masyarakat pada saat sekarang. Pengalaman program yang tidak mempunyai daya ungkit seharusnya perlu dinilai kembali. Perbedaan geografis, analisis perbedaan wilayah perlu dipikirkan untuk pengembangan mekanisme strategi program yang akan dilaksanakan.

\section{Manajemen}

Dengan menggunakan contoh visi Departemen Kesehatan yang sudah membumi untuk mengangkat derajat SDM, perlu diikuti dengan manajemen pelaksanaan program yang selama ini tidak menjadi pertimbangan, misalnya bagaimana agar program berjalan baik di dalam gedung maupun diluar gedung. Apakah tenaganya memadai, apakah motivasi dari tenaga bisa terjadi, bagaimana membangun daya tarik para pekerja agar termotivasi untuk melaksanakan program dengan baik, bagaimana kepemimpinan bisa dibentuk, bagaimana jaringan yang ada, kerjasama, dukungan dan lain sebagainya agar upaya peningkatan SDM tercapai.

\section{KESIMPULAN REKOMENDASI}

DAN 
Indonesia yang pada saat ini menghadapi masalah kualitas SDM yang rendah perlu melakukan kajian strategis agar program yang dilaksanakan dapat memberikan dampak positif. Banyak teknologi serta pengalaman dalam dan luar negeri yang sebenarnya bisa menjadi acuan untuk melakukan kajian strategis untuk menciptakan program yang menguntungkan dan berhasil guna terutama untuk seluruh masyarakat di Indonesia.

Menguatkan komitmen dari berbagai pihak yang terlibat untuk upaya peningkatan SDM sebetulnya dapat dilakukan yang didukung dengan mengaplikasikan strategi komunikasi melalui advokasi, bukti dan solusi yang jelas berdasarkan analsis kebijakan, dan perbaikan manajemen program.

\section{RUJUKAN}

1. Atmarita, 2006. Investasi gizi pada periode kritis dan masa emas anak. Majalah Progizi, Vol. I, 2006. Pusat Promosi Kesehatan, Departemen Kesehatan.

2. Atmarita, 2005. Nutrition Problems in Indonesia. The article and presentation for an integrated international seminar and workshop on Lifestyle - related diseases, Gajah Mada University, 19-20 March 2005

3. Atmarita dan Tatang SF, 2004. Analisa Situasi Masalah Gizi dan
Kesehatan Masyarakat. Wydiakarya National Pangan dan Gizi, Mei 2004.

4. Beckmann, David, and Emily Byers, 2004. "Building political will to end Hunger" Paper prepared for the United Nations Millenium Project Hunger Task Force. Bread for the world, Washington D.C.

5. Gillespie, Stuart, Milla McLachlan, and Roger Shrimpton, eds. 2003. Combating Malnutrition. Time to Act. UNICEF-World Bank Nutrition Assesment. Health, Nutrition, and Population Series. Washington D.C; World Bank, Human Development Network.

6. 2005, Visi, Misi, dan Strategi Departemen Kesehatan 2005-2009.

7. Direktorat Bina Gizi Masyarakat, 2002. Lembar Berita, Jaringan Informasi Pangan dan Gizi, Volume X, No.2. 2002.

8. de Onis $\mathrm{M}$, et.al. WHO Child Growth Standards. Acta Paediatrica, International Journal of Paediatrics. Volume 95 April 2006. Supplement 450.

9. WHO 2006, WHO Child Growth Standards. Methods and Development.

10. World Bank, 2006. Repositioning Nutrition as Central Development. A strategy for large-scale action. Washington D.C. 